\title{
1.28-Tb/s Demultiplexing of an OTDM DPSK Data Signal Using a Silicon Waveguide
}

Ji, Hua; Galili, Michael; Hu, Hao; Pu, Minhao; Oxenløwe, Leif Katsuo; Yvind, Kresten; Hvam, Jørn Märcher; Jeppesen, Palle

Published in:

I E E E Photonics Technology Letters

Link to article, DOI:

10.1109/LPT.2010.2084566

Publication date:

2010

Document Version

Publisher's PDF, also known as Version of record

Link back to DTU Orbit

Citation (APA):

Ji, H., Galili, M., Hu, H., Pu, M., Oxenløwe, L. K., Yvind, K., Hvam, J. M., \& Jeppesen, P. (2010). 1.28-Tb/s Demultiplexing of an OTDM DPSK Data Signal Using a Silicon Waveguide. I E E E Photonics Technology Letters, 22(23), 1762-1764. https://doi.org/10.1109/LPT.2010.2084566

\section{General rights}

Copyright and moral rights for the publications made accessible in the public portal are retained by the authors and/or other copyright owners and it is a condition of accessing publications that users recognise and abide by the legal requirements associated with these rights.

- Users may download and print one copy of any publication from the public portal for the purpose of private study or research.

- You may not further distribute the material or use it for any profit-making activity or commercial gain

- You may freely distribute the URL identifying the publication in the public portal 


\title{
1.28-Tb/s Demultiplexing of an OTDM DPSK Data Signal Using a Silicon Waveguide
}

\author{
Hua Ji, Michael Galili, Hao Hu, Minhao Pu, Leif K. Oxenløwe, Kresten Yvind, Jørn M. Hvam, and Palle Jeppesen
}

\begin{abstract}
This letter demonstrates optical demultiplexing of a 1.28-Tb/s serial differential phase-shift-keying data signal using a nano-engineered silicon waveguide. We first present error-free performance at $640 \mathrm{~Gb} / \mathrm{s}$ and then at $1.28 \mathrm{~Tb} / \mathrm{s}$ with characterization of all 128 channels. Bit-error rates below $10^{-9}$ are achieved for some channels and below forward-error-correction limit for all channels, corresponding to a 1.19-Tb/s error-free data signal.
\end{abstract}

Index Terms-Nano-engineered silicon waveguide, optical communication, ultrafast optical signal processing.

\section{INTRODUCTION}

W ITH THE required capacity of the Internet continuously increasing, terabits-per-second bit rates for Ethernet applications may well be needed soon. To enable this progress, optical time-division-multiplexing (OTDM) systems may be a viable route to explore. For instance, 1.28-Tbaud OTDM-OOK (on-off keying) data generation and demultiplexing have already been demonstrated [1], and using OTDM differential quadrature phase-shift keying (DQPSK) and polarization multiplexing, up to $5.1-\mathrm{Tb} / \mathrm{s}$ signal generation and error-free demodulation using direct detection has also been demonstrated [2]. For these high-speed serial data signals, ultrafast optical switching is necessary. Several materials for optical switching have successfully been demonstrated at $640-1280 \mathrm{~Gb} / \mathrm{s}$, materials such as highly nonlinear fiber (HNLF), periodically poled lithium niobate (PPLN), semiconductor optical amplifiers (SOAs), and chalcogenide waveguides [1], [3]-[5]. In recent years, silicon has been proposed for optical switching [6]. Silicon nanowires in particular are investigated to realize various functionalities for ultra-high-speed serial data, due to their fast response, compactness, robustness, and mature fabrication and processing technology. Four-wave mixing (FWM)-based 10-Gb/s signal regeneration has been demonstrated in a silicon nanowire [7], and very recently $160-\mathrm{Gb} / \mathrm{s}$ demultiplexing and wavelength conversion were also demonstrated in silicon nanowires [8], [9]. In [10], the highest signal processing speed in pure silicon was reported, and the paper demonstrated 1.28-Tb/s all-optical demultiplexing and waveform sampling of an OTDM-OOK data signal, i.e., using the simple amplitude modulation format on-off keying.

Manuscript received July 31, 2010; revised September 23, 2010; accepted September 26, 2010. Date of publication October 07, 2010; date of current version November 17, 2010. This work was supported by the Danish Research Council funded projects NANO-COM and NOSFERATU, by the European Research Council funded project SOCRATES, and by OFS Fitel Denmark.

The authors are with DTU Fotonik, Technical University of Denmark, DK-2800 Lyngby, Denmark (e-mail: huji@ fotonik.dtu.dk).

Color versions of one or more of the figures in this letter are available online at http://ieeexplore.ieee.org.

Digital Object Identifier 10.1109/LPT.2010.2084566

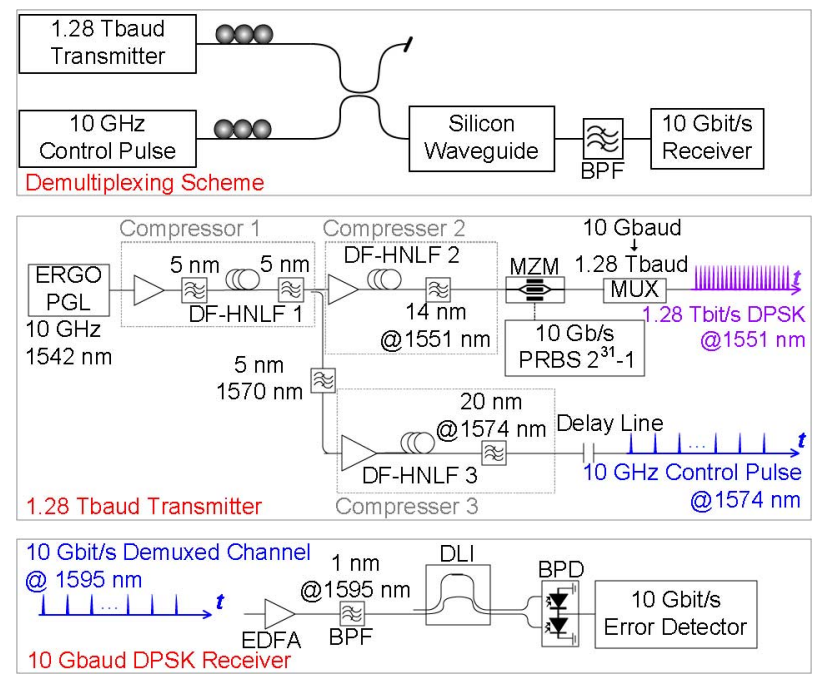

Fig. 1. (Top) Experimental scheme. (Middle) The 1.28-Tbaud transmitter. (Bottom) The 10-Gb/s receiver.

In this letter, we present experimental demonstrations of 640to $10-\mathrm{Gb} / \mathrm{s}$ and $1.28-\mathrm{Tb} / \mathrm{s}$ to $10-\mathrm{Gb} / \mathrm{s}$ demultiplexing of OTDM differential phase-shift-keying (DPSK), i.e., phase modulated data signals. We utilize the phase-preserving effect of FWM for switching in a 5-mm-long silicon nanowire.

\section{EXPERIMENTAL SETUP AND PROCEDURE}

The experimental scheme is shown in Fig. 1 (top). The $1.28-\mathrm{Tb} / \mathrm{s}$ OTDM DPSK data signal generated by the 1.28-Tbaud transmitter [1] is injected into the nano-engineered silicon waveguide together with the $10-\mathrm{GHz}$ control pulse train. Polarization controllers are used to adjust the polarization states of the data signal and control pulse train into the nano-engineered silicon waveguide. This will ensure phase matching and optimize the FWM product in the nano-engineered silicon waveguide. The FWM product will be filtered out using a $5-\mathrm{nm}$ bandpass filter centered at $1595 \mathrm{~nm}$ and then sent into a $10-\mathrm{Gb} / \mathrm{s}$ preamplified $L$-band receiver where the bit-error-rate (BER) performance is measured.

The nano-engineered silicon waveguide used in the experiment is $5 \mathrm{~mm}$ long and its cross-sectional dimensions are $250 \mathrm{~nm} \times 450 \mathrm{~nm}$. It is a silicon-on-insulator (SOI) structure, with the silicon waveguide placed on a $\mathrm{SiO}_{2}$ substrate. The width at the end of the silicon waveguide is tapered from $450 \mathrm{~nm}$ to a tiny tip end of $40 \mathrm{~nm}$ so that the guided mode will be expanded into a polymer waveguide, surrounding the SOI waveguide and the taper. The 5-mm length of the waveguide includes the tapering sections, which are about $1 \mathrm{~mm}$ long each. The cross-sectional dimension of the polymer waveguide matches with the tapered access fibers, reducing the coupling 


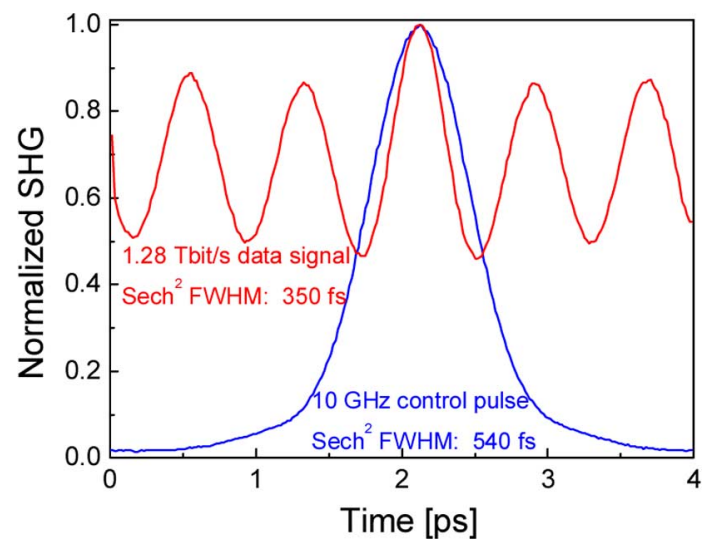

Fig. 2. Autocorrelation traces of the 1.28-Tb/s DPSK signal and 10-GHz control pulses. (The specified FWHMs are for a corresponding $\mathrm{Sech}^{2}$ pulse shape.)

loss [11]. The measured propagation loss is $4.7 \mathrm{~dB} / \mathrm{cm}$ and the device insertion loss is $7 \mathrm{~dB}$.

Fig. 1 (middle) shows how the 1.28-Tbaud OTDM transmitter generates the $1.28-\mathrm{Tb} / \mathrm{s}$ OTDM DPSK data signal. The erbium glass oscillating pulse-generating laser (ERGO-PGL) produces $10-\mathrm{GHz}$ pulses at $1542 \mathrm{~nm}$ with a 1.5 -ps full-width at half-maximum (FWHM) pulsewidth. The spectrum of the pulses is broadened in the 400-m dispersion-flattened highly nonlinear fiber 1 (DF-HNLF 1) (dispersion coefficient $D=-0.45 \mathrm{ps} / \mathrm{nm} / \mathrm{km}$ and dispersion slope $S=0.006 \mathrm{ps} / \mathrm{nm}^{2} / \mathrm{km}$ at $1550 \mathrm{~nm}$, nonlinear coefficient $\gamma=10.5 \mathrm{~W}^{-1} \cdot \mathrm{km}^{-1}$ ) due to self-phase modulation (SPM). The pulse train with broadened spectrum is split into two and filtered at $1551 \mathrm{~nm}$ with a 5-nm optical bandpass filter (BPF) to generate the $10-\mathrm{GHz}$ pulses for the data signal, and using another 5-nm BPF at $1570 \mathrm{~nm}$ to obtain the $10-\mathrm{GHz}$ control pulses. The 10-GHz pulses at $1551 \mathrm{~nm}$ are subjected to further spectral broadening by SPM in the 100-m DF-HNLF $2\left(D=-1.07 \mathrm{ps} / \mathrm{nm} / \mathrm{km}\right.$ and $S=0.004 \mathrm{ps} / \mathrm{nm}^{2} / \mathrm{km}$ at $1560 \mathrm{~nm}, \gamma=10.5 \mathrm{~W}^{-1} \cdot \mathrm{km}^{-1}$ ), and subsequently filtered with a 14-nm BPF at $1551 \mathrm{~nm}$. The strongly chirped pulses are then linearly compressed in time by transmission through the standard single-mode fiber in the remainder of the transmitter. The compressed pulses have 350-fs FWHM width (as shown in Fig. 2) and are then encoded in the DPSK format with $10-\mathrm{Gb} / \mathrm{s}$ PRBS $\left(2^{31}-1\right)$ data using a Mach-Zehnder modulator. The modulated $10-\mathrm{Gb} / \mathrm{s}$ DPSK signal is multiplexed in time using a passive fiber-delay multiplexer $($ MUX $\times 128)$ to generate the $1.28-\mathrm{Tb} / \mathrm{s}$ signal. The other $10-\mathrm{GHz}$ pulses at $1570 \mathrm{~nm}$ are further compressed to 540-fs FWHM (as shown in Fig. 2) in the DF-HNLF3 (200 m, $D=-0.27 \mathrm{ps} / \mathrm{nm} / \mathrm{km}$ and $S=0.005 \mathrm{ps} / \mathrm{nm}^{2} / \mathrm{km}$ at $\left.1560 \mathrm{~nm}, \gamma=10.5 \mathrm{~W}^{-1} \cdot \mathrm{km}^{-1}\right)$. After the silicon waveguide, one demultiplexed channel is filtered out by a $5-\mathrm{nm} \mathrm{BPF}$ and detected by the $10-\mathrm{Gb} / \mathrm{s}$ receiver [shown in Fig. 1 (bottom)]. Here, the demultiplexed 10-Gb/s data signal is preamplified, filtered using a 1-nm BPF and then detected by a 1-symbol delay interferometer (DLI). The output from the DLI is detected using a balanced photodetector (BPD), followed by a $10-\mathrm{Gb} / \mathrm{s}$ error-detector for BER measurement.

\section{EXPERIMENTAL RESULTS AND DISCUSSION}

Fig. 3 shows the spectra measured at the input and output of the nano-engineered silicon waveguide and also measured

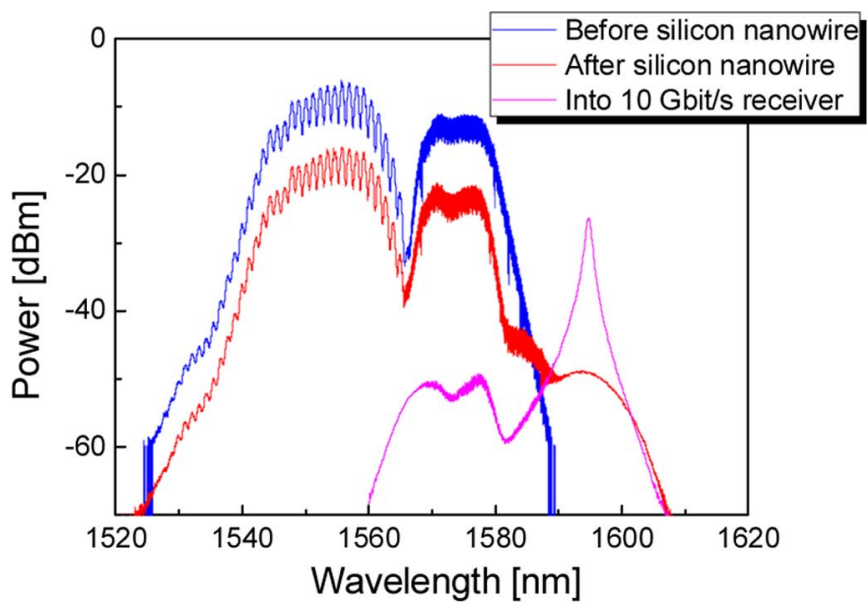

Fig. 3. Optical spectra, measured at input and output of the silicon waveguide, and also at input to the DLI.



Fig. 4. BER curves of four neighboring 10-Gb/s DPSK channels demultiplexed from the $640-\mathrm{Gb} / \mathrm{s}$ OTDM DPSK data signal.

at the input of the $10-\mathrm{Gb} / \mathrm{s}$ receiver. By integrating the optical spectrum of the data and the FWM product at the output of the silicon waveguide, and considering the difference in duty cycle between the pump and data pulses $(\sim 18 \mathrm{~dB})$, the peak fiber-tofiber FWM conversion efficiency is estimated to $-14 \mathrm{~dB}$. These fiber-to-fiber conversion efficiencies include the $7-\mathrm{dB}$ insertion loss.

The BER performance of the demultiplexing using the nanoengineered silicon waveguide is measured both for $640 \mathrm{~Gb} / \mathrm{s}$ and $1.28 \mathrm{~Tb} / \mathrm{s}$. In the $640-$ to $10-\mathrm{Gb} / \mathrm{s}$ demultiplexing, the average power of the data and control signals sent into the silicon waveguide is 13.5 and $14 \mathrm{dBm}$, respectively. Fig. 4 shows the measured BER curves of four neighboring $10-\mathrm{Gb} / \mathrm{s}$ DPSK channels demultiplexed from the 640-Gb/s OTDM DPSK data signal. All four channels show error-free performance, i.e., with a BER $<10^{-9}$. The receiver sensitivity is about $-33 \mathrm{dBm}$, being similar for all channels. However, the BER curves all seem to flatten out, i.e., revealing an error-floor below $10^{-9}$. This error-floor was not present in the OOK demonstration of $640 \mathrm{~Gb} / \mathrm{s}$ and $1.28 \mathrm{~Tb} / \mathrm{s}$ presented in [10] and is believed to be caused by reflections from the particular waveguide used in the experiments presented in the present letter. The reflections will result in interference between data pulses so as to decrease the BER performance.

The 1.28-Tb/s OTDM DPSK data signal is also demultiplexed to $10 \mathrm{~Gb} / \mathrm{s}$ using the nano-engineered silicon waveguide. 




Fig. 5. BER curves of eight neighboring 10-Gb/s DPSK channels demultiplexed from the 1.28- Tb/s OTDM DPSK data signal.

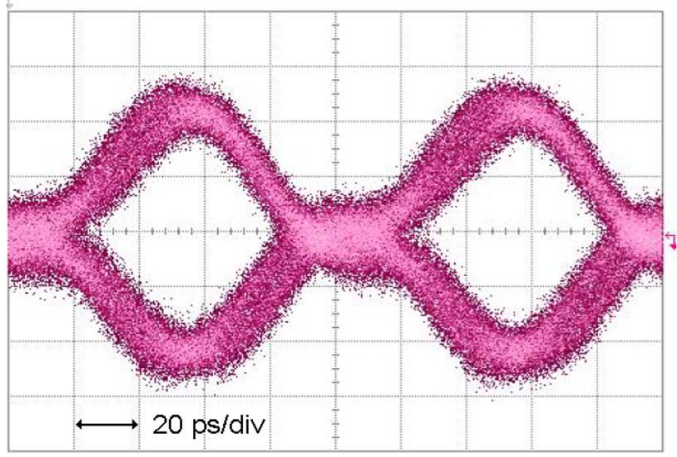

Fig. 6. Clear eye-diagram of a 1.28-Tb/s DPSK demultiplexed channel at errorfree operation.

The average power of the data signal and control signal sent into the silicon waveguide is 16.5 and $14 \mathrm{dBm}$, respectively. Eight neighboring 10-Gb/s DPSK data signal channels are measured to evaluate the BER performance, shown in Fig. 5. Three of the tested channels obtain a BER below $10^{-9}$, one is on the border, and the last four are merely below $10^{-8}$. There is an error-floor between BER $10^{-8}$ and $10^{-9}$. The error-floor cannot be suppressed down to $10^{-9}$ by increasing the power of the data signal or the control pulses. Again, a reflection in the particular silicon waveguide used in these experiments is believed to be the reason for the error-floor. Fig. 6 shows an eye-diagram of a demultiplexed channel at error-free operation. The eye is seen to be clear and open.

In order to characterize all 128 OTDM tributary channels in a practical way, the receiver power for each channel is measured at the relatively high BER of $10^{-4}$. This BER allows for faster measurements, and is still below the standard forward-error-correction (FEC) limit of BER $10^{-3}$. All 128 channels are scanned through and readily yield a BER of $10^{-4}$, i.e., below the FEC limit. Assuming a 7\% FEC redundancy would then lead to a $1.19-\mathrm{Tb} / \mathrm{s}$ data payload, i.e., a 1.19-Tb/s error-free DPSK data signal processed in this silicon nanowire. The results are shown in Fig. 7. There is about 4-dB variation in receiver sensitivity among all the channels. This variation stems from the slight difference among all the channels caused by the multiplexer.

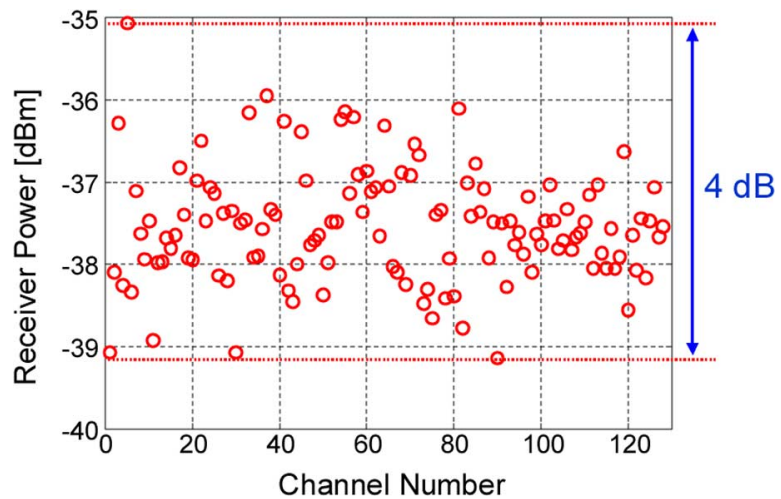

Fig. 7. Receiver sensitivities of all 128 channels at BER $10^{-4}$. All channels are below the $10^{-3}$ FEC limit.

\section{CONCLUSION}

We have experimentally demonstrated $1.28-\mathrm{Tb} / \mathrm{s}$ OTDMDPSK data signal demultiplexing using a nano-engineered silicon waveguide. Error-free operation at BER $10^{-9}$ is achieved. However, an error-floor exists around the $10^{-9}$ level. All 128 channels are demultiplexed and receiver sensitivities are measured at BER $10^{-4}$. There is about $4-\mathrm{dB}$ variation among all the channels. The nano-engineered silicon waveguide shows promising potential for ultrafast optical signal processing.

\section{REFERENCES}

[1] H. C. H. Mulvad, L. K. Oxenløwe, M. Galili, A. T. Clausen, L. GrünerNielsen, and P. Jeppesen, "1.28 Tbit/s single-polarisation OTDM-OOK data generation and demux," Electron. Lett., vol. 45, no. 5, pp. 280-281, Feb. 2009.

[2] H. C. Hansen Mulvad et al., "Demonstration of $5.1 \mathrm{Tbit} / \mathrm{s}$ data capacity on a single-wavelength channel," Opt. Express, vol. 18, no. 2, pp. 1438-1443, 2010.

[3] L. K. Oxenløwe et al., "640 Gbit/s data transmission and clock recovery using an ultra-fast periodically poled lithium niobate device," in Proc. OFC 2008, San Diego, CA, Feb. 24-28, 2008, Paper PDP22.

[4] E. Tangdiongga et al., "All-optical demultiplexing of 640 to $40 \mathrm{Gbits} / \mathrm{s}$ using filtered chirp of a semiconductor optical amplifier," Opt. Lett., vol. 32, no. 7, pp. 835-837, 2007.

[5] T. D. Vo et al., "Photonic chip based $1.28 \mathrm{Tbaud} / \mathrm{s}$ single-polarisation serial OOK transmitter optimization and receiver OTDM switching," in Proc. OFC 2010, San Diego, CA, Mar. 21-26, 2010, Paper PDPC5.

[6] V. R. Almeida, C. A. Barrios, R. R. Panepucci, and M. Lipson, "All-optical control of light on a silicon chip," Nature, vol. 431, pp. 1081-1084, 2004.

[7] R. Salem, M. A. Foster, A. C. Turner, D. F. Geraghty, M. Lipson, and A. L. Gaeta, "Signal regeneration using low power four-wave mixing on silicon chip," Nature Photon., vol. 2, pp. 35-38, 2008.

[8] F. Li et al., "Error-free all-optical demultiplexing at $160 \mathrm{~Gb} / \mathrm{s}$ via FWM in a silicon nanowire," Opt. Express, vol. 18, no. 4, p. 3905, Feb. 2010.

[9] N. Ophir et al., "First 80-Gb/s and 160-Gb/s wavelength converted data stream measurements in a silicon waveguide," in Proc. OFC 2010, San Diego, CA, Mar. 21-26, 2010, Paper OWP5.

[10] H. Ji et al., "1.28 Tbit/s OTDM-OOK data waveform sampling and demultiplexing using silicon nano-wire," in Proc. OFC 2010, San Diego, CA, Mar. 21-26, 2010.

[11] M. Pu, L. Liu, H. Ou, K. Yvind, and J. M. Hvam, "Ultra-low-loss inverted taper coupler for silicon-on-insulator ridge waveguide," Opt. Commun., vol. 283, pp. 3678-3682, Oct. 2010. 